\title{
Assessment of Special Provision for Empowering Diverse Pupils (SPED) Extension Service Project using Context, Input, Process, and Product Evaluation Model (CIPP)
}

\author{
Ericson H. Peñalba \& Denia M. Clacio \\ Teacher Education Department
}

\begin{abstract}
Underlining its role as an agent of empowerment at the community level, the Extension Office of Bulacan State University-Meneses Campus (BulSU-MC) launched in November 2014 an extension service project called Special Provision for Empowering Diverse Pupils (SPED). This university-community partnership had the key objectives of facilitating the transition program for CSNs and raising parents' awareness regarding their children's rights as well as their own rights. Since parents played a central role in the total development of their children, their knowledge and skills were also developed through practical trainings that allowed them to generate alternative sources of income. Considering that no evidence-based evaluation of an extension service project in BulSU-MC had been done using the CIPP model, this study sought to evaluate the three-year implementation of SPED following the principles and procedures of the said model. Employing a mixed methods research design, this study utilized surveys, interviews, observation, and documentary analyses in obtaining data from the beneficiaries of the project. The data informed the thorough evaluation of the project in terms of context, input, process, and product. The socio-economic evaluation of the context under which the project was implemented revealed that they parents were not earning enough to address the needs of their children. The input evaluation advanced the need to improve the operational design of the project in terms of the management and allocation of resources. In terms of the evaluation of process, feedback mechanism was found to be falling short of its function of guiding the project's implementation. Despite the foregoing shortcomings of its operational setup of the project, the product evaluation results found that the project had been responsive to the needs of its target beneficiaries.
\end{abstract}

Keywords: special education, children with special needs, empowerment, CIPP Evaluation Model 


\section{Introduction}

The acquisition of children's skills and abilities can be largely influenced by the interplay of various factors. At the community setting, the full participation of children with special needs (CSNs) reflects the kind of supportive environment that promotes capacity building and inclusion. It is also highly dependent on the legal framework existing at the broader national level, particularly on how their fundamental rights are protected and guaranteed.

In the Philippines, the enactments of laws like Republic Act (R.A.) 7277 (Magna Carta for Persons with Disabilities), R.A. 9155 (Governance of Basic Education Act of 2001), and R.A. 10070 (Institutional Mechanism for the Magna Carta for Disabled Persons) ensure not only the fundamental right to quality, inclusive, and accessible education of CSNs but also the opportunities for the promotion of their well-being. As a response to address the educational needs of CSNs, the Department of Education recognized 648 special education centers in catering to around 350,000 elementary and high school students with exceptionalities (Briones, 2017, as cited in National Economic and Development Authority, 2017).

While such significant measures seem to suggest that policy interventions and services are fully benefitting CSNs, there is still much to be done as regards eliminating the barriers to their full participation and enjoyment of their rights. These constraints include the exclusion of children with disabilities in social protection programs, lack of access to social and medical services in poor localities, prevalence of discrimination, and attitudinal factors (United Nations Children's Fund [Unicef], 2018; Chua et al., 2015).

Among the above barriers, the attitudes of families towards CSNs become crucial to their health-related decisions, restricting them from seeking out social services (Unicef, 2018). Further, the negative experiences (e.g., stress and anxiety) associated with rearing CSNs also result in transformed roles and routines, which would then require interventions to help families address their children's needs (Cavkaytar, Ceyhan, Adiguzel, Uysal, \&Garan, 2012). If parents do not cope well with the demands and stress caring for CSNs, there is also a tendency that they cannot perform certain family functions, thereby affecting their well-being, relationships, and behavior (Barnett, Clements, Kaplan-Estrin, \& Fialka, 2003). 
The challenges encountered by families with CSNs are likely to affect the quality of child care that they need to provide (Collins et al., 2014). It is in this context that families have to empower themselves in fully involving themselves in harnessing the abilities and skills of the children. Empowerment, as defined by Murray, Handyside, Straka and Arton-Titus (2013), refers to the "ability to seek control over one's life by taking action to get what one wants and needs" (p. 146).

The literature on the concept of empowerment has advanced the idea that it can be experienced at three levels namely psychological, organizational, and community (Shultz, Israel, Zimmerman, \&Checkoway, 1995, as cited in Nachsen, 2000). Awareness of one's rights and responsibilities occurs at the psychological level, which can be further translated into concrete actions once a full understanding of one's environment happens (Nachshen, 2000). This has implications for the provision of extension services aimed at making families active partners of change within the organizational and community levels of empowerment. This indicates that parental involvement becomes crucial to the success of programs and services specifically designed for their children with special needs.

From their end, parents and teachers can work closely with service providers whose expertise involves facilitating the skills development of CSNs (Valenzuela, 2017). This collaborative practice not only enhances the transition program, allowing for the provision of services tailored to children's needs, but also enables families to foster empowerment. By continuously engaging families and maximizing their potential as active participants of the delivery of services, they are likely to take initiative in improving their own lives (Samadi, Samadi, \& McConkey, 2015).

\section{Background of the Project}

The Special Provision for Empowering Diverse Pupils (SPED) is an extension service project undertaken by BulSU-MC Extension Office. It was launched in November 2014 as a three-year project consisting of the following components: (1) information educational campaign/advocacy, livelihood/skills training program, and (3) capacity building through transition program. The project has two groups of target beneficiaries: (1) children with special needs (CSNs) enrolled at Marcelo H. Del Pilar Memorial School SPED Center in Bulakan, Bulacan and (2) parents of these CSNs. 
This project has the following objectives: (1) to raise parents' awareness regarding their children's rights as well as their own rights; (2) to improve parents' knowledge and skills through practical trainings; (3) to facilitate the mastery of basic skills of children with special needs as a support to the implementation of the transition program for special education, and (4) to provide parents opportunities for generating alternative sources of income through a livelihood and skills training program.

The project was conducted from November 2014 to February 2018. The activities, which were facilitated by BulSU-MC faculty and student organizations, mostly focused on providing a series of seminar-workshops and trainings to parents. It was also concentrated on facilitating a skills-based transition program for CSNs.

Although the project's title seems to focus only diverse pupils, parents were also given attention to emphasize that the latter should also be empowered to support the total development of their children. A series of seminars (Information Educational Campaign) were organized during the first year of the project's implementation to raise their awareness on human rights. These seminars covered the following topics: (a) children's rights, (b) violence against women and children, (c) gender sensitivity, (d) rights of solo parents, and (e) rights of persons with disabilities. Seminar-workshops (information educational campaign) were also held to improve the parents' knowledge on the following topics: (a) recycling, (b) first aid training, and (c) bamboo propagation.

A key component of the program which was conducted to provide parents opportunities for generating alternative sources of income was livelihood and skills training program. Specifically, the EO conducted a skills-based training on the production of dishwashing liquid and fabric conditioner.

The provision for skill-building workshops (capacity building) for the CSNs was based on the need to conduct transition program for special education, which aims to engage CSNs in activities that would empower and allow them to become productive members of their communities. The following activities were conducted to support the implementation of the transition program: (a) art workshop, (b) music workshop (piano and guitar), (c) no cook food preparation, (d) basic table settings, (e) dish bottle gardening, and (f) weaving. 
To date, no evidence-based evaluation of an extension service project in BulSU-MC had been done using the CIPP model. Hence, this study sought to evaluate the three-year implementation of SPED following the principles and procedures of the said model. The specific objectives were:

1. To determine under what context the project had been implemented.

2. To assess the design and development of communication materials and resource allocation.

3. To assess the processes involved in the project's operations.

4. To evaluate how the project's objectives had been achieved.

\section{Materials and Methods}

This evaluation study employed a mixed methods research design. Specifically, it utilized surveys, interviews, observation, and documentary analyses as the primary means of obtaining data. It was carried out at Marcelo H. Del Pilar Memorial School Special Education Center, which caters to children with learning disability, visual impairment, hearing impairment, mental retardation, behavioral problem, autism, and speech defect. The center, which is one of the 14 learning centers for CSNs in the province of Bulacan, is located at the village of San Nicolas in the coastal municipality of Bulakan.

The population consisted of 35 parents who were the target beneficiaries of the project. Prior to the conduct of the project, they were asked to fill out the needs assessment form which contains the following: (a) personal information, (b) socio-economic status, (c) choices for livelihood skills training program, (d) choices for information education campaign/advocacy and capacity building program, (e) options for special services, (f) options for literacy program, and (g) problems encountered by the family. Data concerning the overall perception of SPED's training components were collected through an evaluation form. The evaluation form consists of 15 items, which were rated on 5-point Likert scales, and 2 open-ended questions, which asked parents what aspect of the project should still be improved and their recommendations.

The project was evaluated using the Context, Input, Process, Product (CIPP) model. Developed by Stufflebeam (1971), the CIPP model advances the idea that programs can be improved for better service provisions to target beneficiaries. It allows implementers to obtain feedbacks which could be useful in deciding on the proper allocation of available resources. As shown in Table 
1, the four phases of the project namely pre-planning, planning, implementation, and post-implementation were evaluated using the model.

Table 1

Evaluation of the four phases the project's implementation using the CIPP model

\begin{tabular}{|c|c|}
\hline Context Evaluation & $\begin{array}{l}\text { Pre-planning } \\
\text { - Needs assessment } \\
\text { - Situation analysis } \\
\end{array}$ \\
\hline Input Evaluation & $\begin{array}{l}\text { Planning } \\
\text { - Work plan development } \\
\text { - Selection of communication strategies } \\
\text { - Development of communication materials } \\
\text { - Selection of extension service providers } \\
\text { - Resource and budget allocation }\end{array}$ \\
\hline Process Evaluation & $\begin{array}{l}\text { Implementation } \\
\text { - Feedback mechanisms } \\
\text { - Documentation and terminal reports }\end{array}$ \\
\hline $\begin{array}{l}\text { Product/Outcome } \\
\text { Evaluation }\end{array}$ & $\begin{array}{l}\text { Post-implementation } \\
\text { - Quantitative evaluation } \\
\text { - Qualitative evaluation }\end{array}$ \\
\hline
\end{tabular}

In studying the context under which the program was implemented, the needs, opportunities, assets, and challenges were assessed to guide decisionmaking and formulation of project's objectives. The researchers examined how needs assessment and situation analysis were conducted during the preplanning stage to characterize the socio-economic environment of the target beneficiaries and institutional environment of BulSU-MC. The work plan and design of the communication approaches utilized during the planning stage were assessed as relevant aspects of input evaluation. Further, the selection of extension team members and allocation of budget and other resources were evaluated as crucial components of the formulation of the project's operational plan.

As regards the assessment of the key processes involved in the implementation of the project, this study focused on how feedback was conveyed to the implementers and how the monitoring of each component of the project was documented through terminal reports. The assessment was geared towards identifying the weaknesses of the project.The last stage of assessment determined the extent to which the project met its objectives. This was done through both quantitative and qualitative evaluations during the postimplementation stage. 


\section{Results and Discussion}

\section{A. Context Evaluation}

The implementers were able to collect and assess background information about the needs of the intended beneficiaries. The problems identified during the assessment were reflected in the process of identifying objectives.

During the pre-planning stage of the first phase of the project, a needs assessment was carried out to determine possible opportunities for addressing the unmet needs of the parents. The assessment reveals that majority of them owned their house and were employed. They were not earning enough to support their families' needs, especially when it comes to supporting their children's studies. When presented with options for a potential livelihood skills training program, they wanted to learn more about how to make fabric conditioner, peanut butter, and dishwashing liquid. It was also revealed that they wanted to improve their knowledge and skills on various issues that affect their own rights as well as the rights of their children with special needs. They were also interested in participating in first aid and environmental conservation trainings.

BulSU-MC was also assessed as regards its capability to meet the objectives of the project. Among the strengths identified was the availability of committed and capable faculty members who could serve as extension service providers. The objectives were evidently formulated based on the above assessment findings. They were aligned to most of the needs highlighted by the parents. These needs included extensions services for livelihood skills training programs and seminars on human rights issues. However, there were needs which topped the list but were not included in the project (e.g., pastry making and massage therapy). According to the lead implementer of the project, what was primarily considered was the 'best fit' between the beneficiaries' needs and the extension service providers' (faculty members) capabilities and expertise.

Prior to the implementation of the second phase, a profiling of the CSNs was done to help the implementers in determining appropriate transition program activities. After seeking recommendations from the SPED center, it was finally agreed that immersions and skills-building workshops should be conducted with the students. Considering that the transition program should facilitate the acquisition of skills towards independent living, such 
interventions were thus necessary and appropriate to achieve the objective of fostering the mastery of basic skills among the students.

\section{B. Input Evaluation}

Work plans were designed based on the needs assessment findings. They were developed based on the existing capabilities of the faculty and resources of the university. In planning the activities, the implementers selected the right communication strategies since they had always been incorporated in various extension service activities of the university and had been proven to foster attitudinal and behavioral changes among the intended beneficiaries. Moreover, since the project also aimed at developing the skills of CSNs, strategies such as one-on-one learning for the transition program and immersion were appropriate to address their assessed needs. It should be noted that the communication materials used particularly for the seminars were not pilot tested. What was only stated in the pre-planning guidelines and processes of BulSU-MC ESO was the generation of appropriate training materials without the need to pilot test them.

In empowering the parents, a series of information, education, and communication campaign (IEC) activities was conducted, focusing on raising awareness on children's rights, rights of persons with disabilities, violence against women and children, and solo parents' rights. Seminar-workshops were also conducted to train parents on first aid training, bamboo propagation, and recycling. Livelihood and skills trainings, which were considered relevant to enabling them foster empowerment at a broader community level, included making peanut butter, dishwashing liquid, fabric conditioner, and acapulco ointment. CSNs were provided skill-building workshops which included art workshop, music workshop (piano and guitar), no cook food preparation, basic table settings, dish bottle gardening, and weaving. All of these activities were conducted at the SPED center, which was equipped with resources and thus was conducive for learning.

Another important consideration was the creation of a team of extension service providers whose capabilities and expertise matched the nature of the activity. It was not difficult at all to determine the composition of the team since there were regular and part-time instructors who had more than two years of experience in conducting extension services and more importantly, were willing to partake in the project. Also involved were instructors who serve as coordinators of Center for Human Rights Education and Gender and 
Development Center.Faculty extensionists were assisted by students from teacher education and industrial technology programs. Specifically, students involved in the transition program of CSNs had semester-long trainings in professional education courses (e.g., Child and Adolescent Development, Learning Assessment Strategies, Home Economics and Livelihood Education, Facilitating Learning, Assessment of Student Learning) that were aligned or related to the conduct of the project.

Furthermore, the resources of the university such as equipment, facilities, and other materials were readily available to the team. The availability of these resources was favorable to most of the extension service providers who were tasked to conduct information educational seminars using audio-visual materials. It also helped that the implementers were resourceful in utilizing materials that were already available. In fact, some of the activities (e.g., seminars and workshops) only required small amount of funds. As regards the expenses that had to be shouldered by the extension service providers, they had to pay only for transportation which could actually be reimbursed. The expenses concerning the materials used in trainings were sourced out from the donations given by private organizations and individuals. Furthermore, the expenses incurred in facilitating skill-building workshops were subsidized by the Department of Education using the budget allocated for eligible activities and expenses (i.e., supplies for Transition program as stipulated in DepEd Order No. 38, s. 2015). Considering these factors, the project can thus be considered cost-effective because it did not cost a lot of money while delivering the optimal use of resources to achieve the desired goals. However, it should be noted that the budget allocation was not specified and stipulated in the operational plan.

\section{Process Evaluation}

Although the plans had been implemented in accordance to the desired outcomes, the importance of acting upon the feedbacks seemed to have been neglected by the implementers. Usually, feedback mechanisms were done either in formal or informal manner. Feedbacks were gathered from the beneficiaries through interviews and evaluation forms (consisting of a combination of close-ended and open-ended questions). The extension service providers, for their part, were tasked to evaluate the process by accomplishing terminal reports (containing a report on the flow of the project and comments raised during the conduct of the activity). 
These feedback mechanisms, however, were not maximized to the fullest. This could be attributed to two reasons. First, they were only kept for filing, not for assessing and discussing with the staff the potential challenges or suggestions for the improvement of the project. Second, the BulSU-MC EO did not have a specific evaluation team tasked to monitor the implementation of the project. The office's existing operational setup engaged extension service providers to perform their tasks only prior to and during the implementation of the project. Hence, to date, there have been no formal written reports on the evaluation findings presented to the beneficiaries and everyone involved in the project. The reports were particularly crucial in determining whether the management of resources, budget, and staff was still relevant to the conduct of the plan.

\section{Product Evaluation}

\section{Quantitative Evaluation Results}

The quantitative product evaluation results indicated that majority $(63.3 \%)$ of the parents strongly agreed on how each component of the project was carried out. As shown in Table 2, a large majority (74.3\%) of them strongly agreed that the contents of the trainings and seminars well-organized and easyto-follow, the knowledge shared by the implementers were beneficial to them, and the amount of time allotted for the open forum was enough.

Furthermore, majority $(68.6 \%)$ of parents strongly agreed that the extension service providers were knowledgeable about the topics. Majority $(65.7 \%)$ of them also strongly agreed that the project was able to meet their expectations, the quality of the trainings and seminars was ensured, and the allotted time for each training and seminar was enough. Relatively few (17.1\%) of them, however, were undecided regarding the timeliness and appropriateness of the trainings and seminars to their current needs.

Table 2

Frequency distribution of parents' attitudes toward SPED project's implementation

\begin{tabular}{lcccccccccc}
\hline \multicolumn{1}{c}{ Statement } & \multicolumn{2}{c}{$\begin{array}{c}\text { Strongly } \\
\text { agree }\end{array}$} & Agree & $\begin{array}{c}\text { Neither } \\
\text { agree nor } \\
\text { disagree }\end{array}$ & Disagree & \multicolumn{2}{c}{$\begin{array}{c}\text { Strongly } \\
\text { disagree }\end{array}$} \\
\cline { 2 - 12 } & F & $\%$ & F & $\%$ & F & $\%$ & F & $\%$ & F & $\%$ \\
\hline $\begin{array}{l}\text { 1. My expectations } \\
\text { about the project } \\
\text { were achieved. }\end{array}$ & 23 & 65.7 & 10 & 28.6 & 2 & 5.7 & - & - & - & - \\
\hline
\end{tabular}


2. The knowledge gained from the project could be applied in future

endeavors.

3. The objectives per training and seminar were accomplished.

4. The contents of each training and seminar were organized and could be easily followed. 5. The knowledge shared by the project's implementers was useful.

6. The resources shared by the project's implementers were useful.

7. The trainings and seminars are timely and appropriate to our current needs.

8. The speakers and trainors are knowledgeable about the topics. 9. The quality of each training and seminar is ensured. 10. The speakers and trainors were able to address each topic's objective. 11. Participation, cooperation, and interaction among the participants were encouraged. 12. The sharing of insights among the participants was allowed.

13. There was enough amount of $\begin{array}{llllll}22 & 62.9 & 9 & 25.7 & 4 & 11.4\end{array}$

$\begin{array}{llllll}26 & 74.3 & 7 & 20.0 & 2 & 5.7\end{array}$

$\begin{array}{llllll}26 & 74.3 & 8 & 22.9 & 1 & 2.9\end{array}$

$\begin{array}{llllll}19 & 54.3 & 15 & 42.9 & 1 & 2.9\end{array}$

$\begin{array}{llllll}16 & 45.7 & 13 & 37.1 & 6 & 17.1\end{array}$

$\begin{array}{llllll}24 & 68.6 & 8 & 22.9 & 3 & 8.6\end{array}$

$\begin{array}{llllll}23 & 65.7 & 11 & 31.4 & 1 & 2.9\end{array}$

$\begin{array}{llllll}20 & 57.1 & 13 & 37.1 & 2 & 5.7\end{array}$

$\begin{array}{llllll}21 & 60.0 & 12 & 34.3 & 2 & 5.7\end{array}$

$\begin{array}{llllll}22 & 62.9 & 10 & 28.6 & 3 & 8.6\end{array}$

$\begin{array}{llllll}23 & 65.7 & 10 & 28.6 & 1 & 2.9\end{array}$ 
14. There was enough amount of time allotted for the 26 open forum.

\begin{tabular}{llllllllllll}
\hline $\begin{array}{l}\text { Average frequency/ } \\
\text { percentage }\end{array}$ & 22.1 & 63.3 & 10.5 & 30.0 & 2.2 & 6.3 & 0.1 & 0.4 & - & -
\end{tabular}

Table 3

Frequency distribution of parents' overall attitude toward SPED project's implementation

\begin{tabular}{lcccccccccc}
\hline \multirow{2}{*}{ Statement } & \multicolumn{2}{c}{ Excellent } & \multicolumn{2}{c}{ Very good } & \multicolumn{2}{c}{ Good } & \multicolumn{2}{c}{ Fair } & \multicolumn{2}{c}{ Poor } \\
\cline { 2 - 11 } & $\mathrm{F}$ & $\%$ & $\mathrm{~F}$ & $\%$ & $\mathrm{~F}$ & $\%$ & $\mathrm{~F}$ & $\%$ & $\mathrm{~F}$ & $\%$ \\
\hline $\begin{array}{l}\text { 15. Overall, how will } \\
\text { you rate the quality the } \\
\text { project? }\end{array}$ & 21 & 60.0 & 5 & 14.3 & 5 & 14.3 & 4 & 11.4 & - & - \\
\hline
\end{tabular}

In general, as indicated in Table 3, majority (60.0\%) of the parents perceived SPED as an excellent extension service project. Only $11.4 \%$ of them gave a fair rating of the project.

\section{Qualitative Evaluation Results}

The qualitative evaluation results reveal that the parents had a deeper understanding of what their children could achieve and do. They stated that their children were able to improve their interpersonal communication skills, develop self-esteem, and demonstrate skills independently (e.g., writing, planting and growing plants, recycling, doing household chores). These changes were reflected in the following statements:

"He learned how to socialize with other children. He was able to overcome his shyness. He learned new things, be it academic or extracurricular."

"My child gained confidence and learned more from participating in extra-curricular activities and even from doing chores."

"This project of BulSU-Meneses Campus had really helped my child a lot. She learned how to interact with others, how to grow plants, and create things out of recycled materials." 
At the personal level, the parents recognized how the project had changed their perspectives on how to care for their children. They shared that they gained a better understanding of their children's physical and learning conditions. As shared by three parents:

"They (project implementers) challenged us, parents, to continue guiding our children as they acquire more knowledge and skills."

"What I learned from this project is to have more patience when guiding them as they engage in different activities.'

"Because of the untiring support of the campus to our special education center, I gained hope for my child's development. I learned how to properly handle the behavior of my child."

The seminars and trainings were beneficial in increasing parents' level of that awareness on their rights as well as the rights of their children. They also acknowledged skills-building workshops were of great help in the implementation of the transition program, enabling their children to master basic skills like creating actual artistic products and playing musical instruments. As shared by the president of the association of parents of CSNs:

"Everything that you shared with us was really instilled in our hearts and minds - the benefits that can be enjoyed by persons with disabilities, the rights of solo parents, and our rights as Filipino citizens.”

The parents also highlighted the relevance of the skills training programs in encouraging them to become more productive and engage in livelihood opportunities. They regarded the different training sessions relevant to their well-being. As evidenced in the following comments of two beneficiaries:

"We learned how to create dishwashing liquid and fabric conditioner, and other products that can be beneficial to our livelihood."

"One of the things I learned is that there are so many things that we can create out of materials which we think no longer have value. We learned how to be patient and industrious with their (implementers) help ... to tap into and improve our hidden skills" 


\section{Conclusions and Recommendations}

From the obtained results of the CIPP evaluation, the following lessons and implications can be drawn. First, the results of context evaluation suggest that needs assessment should be done as a means to satisfy the immediate needs of the target beneficiaries. While a possible problem may arise from the lack of extension service providers who are experts on the priority needs, this can be addressed by tapping the expertise of other colleges and campuses and organizations such as government line agencies, non-government organizations, and cooperatives. This may then serve as an opportunity for establishing long-term linkages and exercising shared stakeholdership with these organizations.

Second, the input evaluation findings indicate the need to pilot test the communication materials and include this activity as part of the pre-planning guidelines followed by BulSU-MC ESO. This would require the creation of a team directly responsible for monitoring and documenting the project's trial run. This may then have important implications for the provision for additional budget and the need to look for a pilot group which is demographically similar to the project's intended beneficiaries. Moreover, although it was evident that the project was successfully implemented in a cost-effective manner, there is still much work to be done in terms of managing resources and staff in accordance to the allocated budget. In this regard, budget should be clearly specified per activity. This is relevant in informing present and future decisions concerning the optimal use of funds.

Third, the process evaluation underscores the significance of feedback mechanism to ensure that the extension service providers are fully informed of the possible defects occurring during the implementation. If possible, meetings should be held regularly to discuss what need to be altered or improved in the design of the project. This indicates the need to communicate the contents of all documents and terminal reports immediately after the conclusion of the project. This need for the dissemination of feedback information, which is an essential component of process evaluation, should then be stipulated in the guidelines followed by the university's extension office in evaluating its various programs.

Fourth, in the context of product/outcome evaluation, the positive evaluation findings should be seen as an opportunity to further assess the overall design of the program. This is to ensure that such positive results can 
be translated into the project's effectiveness. The weaknesses in the design of the project can be immediately addressed through the creation of an evaluation team that would specifically deal with the monitoring and evaluation of all implementation activities. This is to ensure that feedbacks are appropriately incorporated in decisions that would require the implementers to either maintain or modify the plans or the overall design of the project.

Overall, the positive quantitative and qualitative evaluation feedbacks show that the project had been responsive to the needs of the target beneficiaries. This became possible since the project catered to the needs of individuals who were appropriately selected as the intended beneficiaries. The extent to which the program had served them can be explained not only in terms of the perceived changes in their attitudes but also as regards the actual transformations in their conditions. Even the people (i.e., special education teacher-in-charge and principal) who worked closely with the extension service providers acknowledged how the project made a significant difference to the beneficiaries. In this regard, there is a need not only to continue the implementation SPED extension service project for another three-year phase but also to make necessary improvements on its operational design informed by the results of the CIPP evaluation.

\section{References}

Barnett, D., Clements, M., Kaplan-Estrin, M., \&Fialka, J. (2003). Building new dreams: Supporting parents' adaptation to their child with special needs. Infants and Young Children, 16(3), 184-200.

Cavkaytar, A. Ceyhan, E., Adiguzel, O.C., Uysal, H., \&Garan, O. (2012). Investigating education and support needs of families who have children with intellectual disabilities. Turkish Online Journal of Qualitative Inquiry, 3(4), 79-99.

Chua, Y.T., Cruz, B., Olarte, A.M., Ordenes, L., Paredes, A.K., Soriano, J., \&Tordesillas, E. (2015). Getting it right: Reporting on disability in the Philippines. Retrieved from The Asia Foundation Website: https://asiafoundation.org/wp-content/uploads/2018/03/Getting-It-Right.Reporting-on-Disability-in-the-Philippines.pdf

Collins, C.C., Fischer, R., \&Lalich, N. (2014). Enhancing child care for children with special needs through technical assistance. Journal of Family Strengths,14(1). 1-37. Retrieved from http://digitalcommons.library.tmc.edu/jfs/vol14/iss1/9 
Murray, M.M., Handyside, L.M., Straka, L.A., \&Arton-Titus, T.V. (2013). Parent empowerment: Connecting with preservice special education teachers.School Community Journal, 23(1), 145-168.

Nachshen, J.S. (2000). Empowerment and families: Building bridges between parents and professionals, theory and research. Journal on Developmental Disabilities, 11(1), 67-75.

National Economic and Development Authority. (2017). Socioeconomic report 2017. Retrieved from NEDA website: https://www.neda.gov.ph/2018/03/20/ser2017/

Samadi, S.A., Samadi, H., \&McConkey, R. (2015). A conceptual model for empowering families in less affluent countries who have a child with autism. In M. Fitzgerald (Ed.), Autism Spectrum Disorder: Recent Advances (pp. 231-244). doi:10.5772/58507

Stufflebeam, D.L. (1971, February). The relevance of the CIPP evaluation model for educational accountability. Paper presented at the Annual Meeting of the American Association of School Administrators, Atlantic City, NJ. Retrieved from https://files.eric.ed.gov/fulltext/ED062385.pdf

United Nations Children's Fund. (2018). Children with disabilities: Finding the way to an inclusive service framework (Policy Brief No. 6). Retrieved from https://www.unicef.org/philippines/CWDSitanPolicyBrief.pdf

Valenzuela, M.L.S. (2017, October). Proposed Philippine model of collaboration for children with autism given interdisciplinary experiences. Proceedings of Academicsera International Conference, New York, USA, $1-8$. 